\title{
Diagnosis and Treatment of Acute Acromioclavicular Joint Injuries
}

\author{
Maurice Balke ${ }^{1, *}$ \\ ${ }^{1}$ Sports Clinic Cologne, Department of Sports Traumatology, Cologne Merheim Medical Center, University of Witten/Herdecke, Cologne, Germany \\ "Corresponding author: Maurice Balke, Sports Clinic Cologne, Department of Sports Traumatology, Cologne Merheim Medical Center, University of Witten/Herdecke, \\ Ostmerheimer Strasse 200, 51109 Cologne, Germany. Tel: + 49-221880728, E-mail: maurice.balke@gmail.com
}

Received 2016 June 21; Revised 2016 July 27; Accepted 2016 August 04.

\begin{abstract}
Context: Acute acromioclavicular joint (ACJ) dislocations are very common in young and active adults. Despite the high incidence of this injury, there is still some controversy on its diagnosis and treatment.

Evidence Acquisition: This review was based on the knowledge of the current literature listed in PubMed. It summarizes the current strategies for acute $\mathrm{AC}$ joint injuries.

Results: Acute injuries of the AC joint are very common among active individuals. Most authors recommend panorama- (stress-) view radiographs and additional radiographs for the horizontal instability. Low-grade injuries (Rockwood I-II) should be treated conservatively whereas high-grade injuries (Rockwood IV-VI) are best treated surgically. The most appropriate treatment for Rockwood III injuries is still a matter of debate and should be recommended based on the individual needs of the patient.

Conclusions: Based on the current literature, there still is no gold standard for the diagnosis of acute AC joint injuries. As surgical techniques, the hook plate as well as the arthroscopic button techniques are commonly used leading to good and reproducible results. However, evidence of the superiority of these techniques over alternative methods is lacking.
\end{abstract}

Keywords: Rockwood, Tossy, Acromio-Clavicular Joint, ACJ, Hook Plate, TightRope

\section{Context}

Acute acromioclavicular joint (ACJ) dislocations are very common in young and active adults. Despite the high incidence of this injury, there is still some controversy on its diagnosis and treatment. There is an ongoing discussion among experts if plain radiographs or bilateral stress radiographs are sufficient or if special dynamic radiographs or even MRI are necessary to evaluate the grade of injury. According to the treatment, there is consensus that low-grade injuries (Rockwood I and II) are best treated nonoperatively and high-grade injuries (Rockwood IV to VI) are best treated surgically (1). If the very common Rockwood III injuries should be operated on (2-11) and which surgical technique leads to the best results is still unclear. A recent meta-analysis by Beitzel et al. found 151 different surgical techniques for ACJ reconstruction in the literature (9). This high number shows that there is no gold standard for the surgical treatment. In their literature review they found 14 scientific articles comparing conservative to surgical treatment of ACJ injuries. Eleven were retrospective level III studies and only three were prospective level II studies (9). According to these studies, neither conservative nor surgical therapy has been shown to be preferable. There was no superiority of one of the many surgical techniques.

Our own study group recently published a survey on the diagnosis and treatment among trauma and orthope- dic surgeons in Germany (1) and compared the results to a similar study conducted more than 10 years ago (12). Since the first survey published in 2001 (12), new minimally invasive (13) and arthroscopic techniques have been introduced $(14,15)$.

In $2014,73 \%$ of the participating surgeons recommended surgical treatment for acute Rockwood III injuries (1), 11\% less than in 2001 with $84 \%$ (12). Preferred surgical techniques for the treatment of acute ACJ injuries changed dramatically over the last 10 years at least in Germany. Whereas in 2001 the preferred techniques were the transfixation of the ACJ and the coracoclavicular cerclage (12), most surgeons now prefer the hook plate followed by the arthroscopic TightRope technique (1). The latter is most commonly used by surgeons specialized in arthroscopy and shoulder surgery (16). Since there are no proofs in the literature showing an advantage of the hook plate or TightRope over other techniques, the reasons for these changes remain speculative.

This article aimed to give an overview of the current diagnosis and treatment modalities for acute ACJ injuries.

\section{Evidence Acquisition}

This review was based on the knowledge of the current literature listed in PubMed. It summarizes the current strategies for acute AC joint injuries. 


\section{Results}

\subsection{Epidemiology}

ACJ sprains or dislocations are very common injuries among active, mostly male, adults and represent $12 \%$ of all injuries of the shoulder girdle (17-22). Common causes of ACJ injuries are falls, in most cases sports related. A high incidence is found in sports with a high frequency of falls like alpine skiing, were $20 \%$ of all injuries affect the ACJ (23$25)$, or sports with high impact forces like rugby (26) or ice hockey (27).

ACJ dislocations can either be caused by a direct or indirect mechanism. Mostly a direct fall on the shoulder with an adducted arm leads to inferior and medial displacement of the acromion and scapula. Depending on the impact force first the ACJ capsule fails followed by tearing of the coracoclavicular (CC-) ligaments, and in some cases avulsion of the deltotrapezoid fascia.

\subsection{Classification}

In 1917, Cadenet published a classification for ACJ injuries recognizing the sequential injury mechanism (28). He described the involvement of the acromioclavicular (AC) and coracoclavicular (CC) ligaments as well as the deltoid and trapezoid muscles depending on the energy of the impact. His findings were the basis for the classification by Tossy et al. published in 1963 that is still very popular today (29). A type I injury included an isolated incomplete AC ligament injury, type II a complete AC and incomplete CC ligament injury, and type III complete injuries of both, the AC and CC ligaments. The grade of the injury was diagnosed by the amount of displacement of the lateral clavicle with respect to the acromion on plain anteroposterior radiographs. An evaluation of a possible dislocation in the horizontal plane was not part of these early classification systems. Based on the descriptions by Tossy et al. Rockwood in 1984 published an extended classification system, which still represents the standard for grading ACJ injuries (30). Rockwood added three new grades of injuries: Type IV represents a horizontal displacement of the distal clavicle, type $\mathrm{V}$ a complete displacement of the distal clavicle with disruption of the delto-trapezoid fascia (in addition to the Tossy type III), and type VI an inferior displacement of the distal clavicle beneath the coracoid process. The latter is only described in case reports. Thirty-four percent of participants of a survey among orthopedic surgeons in Germany indicated that they have never seen such an injury (16). In a recent study our group (Schneider et al.) evaluated the inter- and intraobserver reliability of the Rockwood classification in acute ACJ dislocations. The authors concluded that acute ACJ injuries can be reliably classified according to Rockwood on bilateral stress radiographs and axial radiographs (31).

However, a major drawback of the current classifications is the lack of an evaluation of dynamic or multidirectional instabilities.

A newly developed acromioclavicular joint instability (ACJI) score inaugurated by Scheibel et al. (32) uses Alexander view radiographs (33) to evaluate dynamic horizontal instability. The ACJI has a maximum of 100 points and consists of 5 subitems: Pain (20 points), activities of daily living (10 points), cosmesis (10 points), function ( 25 points), and radiological assessment (35 points, bilateral stress views and Alexander view). Thus, this score combines subjective and objective parameters also addressing the horizontal instability (32).

\subsection{Diagnosis}

The clinical examination is still of high importance to evaluate the severity of acute ACJ injuries. Swelling, hematoma and local tenderness over the ACJ are common clinical findings. In some cases the cranial dislocation (step formation) of the lateral clavicle is clearly visible or can be palpated. If pain and swelling allow, the examiner can also evaluate the reducibility and horizontal instability. All findings should be compared to the contralateral healthy shoulder, because some patients have a physiologically prominent lateral clavicle.

\subsubsection{Imaging}

Typically plain radiographs are performed to exclude fractures of the shoulder girdle. The recent survey among orthopedic and trauma surgeons also asked for the commonly used radiographic diagnostics (1). Ninety percent of participants regularly performed bilateral stress radiographs, 79\% true anteroposterior, 59\% Y- or outlet-view radiographs, and 44\% projections according to Zanca (34). Only $42 \%$ regularly performed radiographs for evaluating horizontal instability (axial view) and only 12\% performed dynamic Alexander view radiographs. Thus, one can assume that more than $40 \%$ are not able to exclude the horizontal instability and are not able to correctly classify the injury. In cases of acute ACJ injuries less than 5\% regularly recommend MRI or computed tomography (1).

For the bilateral stress view, the patient is positioned in neutral position in front of the x-ray cassette with a 10 $\mathrm{kg}$ weight hanging on both wrists and the X-ray beam is tilted $10^{\circ}$ caudo-cranial. Thus, the AC and the CC distance can be measured and compared with the healthy side. Normally the AC distance measures 1 to $3 \mathrm{~mm}$. A distance of more than 6 (women) or 7 (men) mm was described to be pathologic (35). To detect a posterior dislocation of the distal clavicle, a second plane is mandatory. Most commonly 
the axillary (axial) view is used. Rockwood did not define the exact position of the patient (sitting, supine, or standing), but in most departments the sitting position is most practical. Usually the arm is abducted $90^{\circ}$ leading to a shift of the distal clavicle over the acromion in case of an acute ACJ injury. Unfortunately the axillary view has a high risk of errors due to the projection as well as the arm position. If the projection and arm position are correct in healthy shoulders, the anterior border of the clavicle and the anterior border of the acromion are in line. The extent of a posterior shift of the distal clavicle can be measured if present.

For the Alexander view mentioned above a modification of a true lateral scapula view is used to detect the posterior dislocation of the distal clavicle (33). The patient is positioned sitting or standing and the shoulders are thrust forward. In cases of acute ACJ injuries the distal clavicle will overlap the acromion and be displaced superiorly.

Both techniques only enable to detect a static horizontal instability but will miss a potential dynamic instability. Therefore, radiographs can be performed with the arm in different angles of abduction and elevation $(32,36)$.

The magnetic resonance imaging (MRI) can be helpful in diagnosing acute ACJ injuries. The affection of the capsule, the delto-trapezoidal fascia, the AC-, and the CCligaments can be detected enabling to diagnose type I injuries and to differentiate between type II and III injuries (37-39). Despite these advantages, MRI is not necessary in most cases and should not be the diagnostic instrument of the first choice (40). MRI often leads to an overestimation of the injury and has been reported to inadequately correlate with clinical and radiographic findings (37). If MRI is considered a coronal oblique plane parallel to the distal clavicle and the ACJ should be performed instead of a conventional orientation. Thus, the CC ligaments are visualized and tears can be reliably detected (39). Additionally sagittal and axial planes are recommended.

In the evaluation of acute ACJ injuries, the author routinely performs bilateral stress views and axial (axillary) views of the affected shoulder. Together with the clinical examination a correct grading and thus correct treatment is possible in most cases. If in doubt dynamic axillary views and in selected cases MRI can be added.

\subsection{Treatment}

Treatment options for ACJ injuries range from "skillful neglect" to complex surgical procedures. There is consensus that low-grade injuries (Rockwood I-II) can successfully be treated conservatively while high-grade injuries (Rockwood IV - VI) are better treated surgically $(1,16)$. For Rockwood III injuries the best treatment option is still a matter of debate, since conservative as well as surgical procedures can lead to good results (3-9). In a recent survey among surgeons about 70\% recommend surgical stabilization for Rockwood III injuries (16).

\subsubsection{Nonoperative Treatment}

In the current literature there is no standard conservative treatment. Recommendations vary from functional exercises without any immobilization to various attempts of closed reductions (41-44). External immobilizations, such as straps, casting techniques, tapes or traction methods might lead to skin irritations by applying pressure on the lateral clavicle. Due to these drawbacks and the lack of compliance in the young and active patients the author prefers the "skillful neglect" with immobilization in a simple shoulder sling for the first 3 to 7 days until pain has resolved. This is accompanied by pain medication and physical therapy (29). Patients are typically free of pain and have a full range of motion after 3 to 4 weeks, which enables to return to sports quickly.

Conservative treatment is the treatment of choice for Rockwood I and II injuries, and some Rockwood III injuries. Whereas the outcome is good in most cases it has to be considered that some patients present with persistent pain and instability after several weeks leading to chronic complaints. This may be caused by persistent horizontal instability that might not have been recognized during the initial consultation. Especially a dynamic horizontal instability is often missed even by axial radiographs. Taken into account that only around $40 \%$ commonly perform radiographs to detect the horizontal component $(1,16)$, the rate of Rockwood IV injuries that have been misdiagnosed as Rockwood II injuries or injuries with a dynamic instability might be relatively high. Despite that there are studies showing that some patients develop complaints over time leading to unsatisfactory results. Moushine et al. published in 2003 that 26 months after conservative treatment of Rockwood I and II injuries, 27\% (9 out of 33 patients) had surgery of the AC joint, and 21\% (24 patients) of the patients not needing surgery were not satisfied with the result (45). Mikek et al. followed conservatively treated Rockwood I and II injuries for 10.2 years and found that $52 \%$ (12 out of 23 patients) had complaints with their AC joint. Specific shoulder scores such as the Constant score, UCLA score, and the simple shoulder test were significantly worse compared to the healthy shoulder (46). On the other hand, Joukainen recently published a study on Rockwood III and V injuries comparing 9 patients treated by external reduction for 4 weeks with 16 patients surgically treated with a temporary K-wire stabilization (implant removal after 6 weeks). He did not find significant differences regarding the outcome. There is an ongoing randomized controlled trial in the United Kingdom comparing open reduction versus nonoperative treatment for the management 
of acute grade III and IV AC joint injuries (ISRCTN47376242, DOI 10.1186/ISRCTN47376242). Probably the results will give further advices for the best treatment modalities. However, the author believes that ruling out a static or dynamic horizontal component of instability is a key to a successful conservative treatment (36).

Despite persistent instability, tears of the articular disc as well as posttraumatic arthritis might also cause pain even years after the initial injury. Whereas most cases of posttraumatic changes have no clinical relevance (7) symptomatic patients can usually be successfully treated by arthroscopic AC joint resection.

\subsubsection{Surgical Treatment}

There is consensus in the literature that high grade Rockwood IV to VI and some grade III injuries should be treated surgically. However, there is still no surgical technique that can be regarded as a gold standard. In a recent review article, Beitzel et al. found 151 different surgical techniques for AC joint reconstruction in the literature (9). Within the last 10 years, arthroscopic as well as minimally invasive techniques have gained more and more popularity. According to the recent survey published by the author, the preferences for specific surgical techniques have changed over the last decade (1). In 2001, 39\% of surgeons preferred acromio-clavicular transfixation with Kwires followed by coraco-clavicular cerclages in $32 \%$. Only $22 \%$ commonly used a hook plate. Arthroscopic techniques (e.g. TighRope) were not available. In 2013 only $6 \%$ still preferred the transfixation, and only $11 \%$ coraco-clavicular cerclages. Nowadays, at least among orthopedic surgeons in Germany, the most common surgical technique is the hook plate which is used by $44 \%$, followed by arthroscopic techniques (TightRope) in 27\% (1).

Concerning the timing of the surgery there is consensus that acute cases should be treated within the first 2 weeks after trauma (1), if the aim of the surgery is healing of the native torn ligaments and capsule. In chronic cases other procedures with the use of grafts are necessary, which is not part of the present review.

Due to the plethora of available surgical techniques, this article focuses on the two most common procedures, the hook plate, and the arthroscopic/minimally invasive button fixation (e.g. TightRope). This does not mean that other surgical procedures like cerclages or AC joint transfixation might not lead to similar results.

\subsubsection{Hook Plate}

The original hook plate was introduced in 1976 by Balser et al. and consisted of a plate that is fixed with screws on the lateral clavicle and a hook that is introduced through the AC joint and engaged under the acromion
(47). After modifications of the original design the hook of modern implants dos not pass directly through the AC joint but more dorsal preventing further damage of the joint. This implant gained more and more popularity providing reproducible results, but still has the drawback of implant removal. Gstettner et al. compared conservative treatment to hook plate stabilization in Rockwood III injuries and reported significantly better clinical as well as radiological results for the latter (8). Similar data were published by Kienast et al. who found good to excellent results in $84 \%$ of 225 patients with AC joint dislocations type III to V. However, they also noted a complication rate of $10.6 \%$ (48). These good results were also reported by Salem et al. (49) and Di Francesco et al. (50); however, both published a loss of reduction in $35 \%$, respectively $12 \%$ of cases after plate removal.

Common complications are osteolysis or fractures of the acromion due to the subacromial hook as well as subacromial irritations (51). Thus, immobilization is recommended and plate removal is necessary, which is performed usually after 3 months.

\subsubsection{Arthroscopic / Minimally Invasive Techniques}

Arthroscopic techniques for reconstruction of the AC joint have first been described by Wolf et al. using polyethylene cerclages. They achieved $81 \%$ good and excellent results in 21 patients with Rockwood type III to $\mathrm{V}$ injuries (52). Originally produced for stabilization of the ankle syndesmosis, the TightRope system (Arthrex, Naples, FL/USA) has gained more and more popularity for AC joint reconstruction. The original construct consisted of two flip buttons connected by a \#5 FiberWire suture (Arthrex). Holes with a diameter of $4 \mathrm{~mm}$ were drilled through the coracoid process as well as through the clavicle using special guiding devices. One button was flipped under the coracoid process and the other over the clavicle. By tying the knots over the clavicular button the lateral clavicle is reduced and hold in place until the coraco-clavicular ligaments have healed. Due to relatively high rates of recurrent subluxation and dislocation, the design of the implant has been modified. Nowadays, greater diameter buttons are used and two clavicular buttons are recommended (the second generation double TightRope) (32). By placing the two drill holes at the insertion sites of the coraco-clavicular ligaments an anatomic reconstruction can be achieved that has comparable biomechanical properties to the native AC joint (53). Due to persistent horizontal instability in high-grade injuries some authors advocate an additional acromio-clavicular stabilization (54). Whether this additional procedure is necessary remains to be seen. The principle of this arthroscopic button technique can also be used in a minimally invasive open pro- 
cedure. Usually a saber-cut of $4 \mathrm{~cm}$ length is used and the drill holes are placed using special aiming devices. In open procedures, the torn clavipectoral fascia can also be addressed and repaired adding additional stability. Comparable systems like the MINAR (minimally invasive ACJ reconstruction) (Karl Storz; Tuttlingen, Germany) (55) or the TwinBridge system (Smith and Nephew) have been developed. Most authors see an advantage of the arthroscopic technique in being able to recognize and if necessary treat concomitant injuries of the glenohumeral joint. Superior labral tear from anterior to posterior (SLAP) lesions or (partial) rotator cuff tears are present in $18 \%$ to $22 \%(56,57)$. The relevance of these injuries and their relation to the trauma are still a matter of discussion. Moreover, other techniques (e.g. the hook plate) also allow additional arthroscopy if favored by the surgeon.

Few studies compare the hook plate to the double TightRope. Jensen et al. found comparable clinical as well as radiological results but preferred the TightRope due to the possibility to recognize and treat concomitant injuries and because an implant removal is not necessary $(56,58)$. In both groups the coraco-clavicular distance at final follow-up was significantly greater compared to the healthy shoulder and the complication rates of $13 \%$ for the hook plate and $12 \%$ for the double TightRope were relatively high (58).

As stated by Beitzel et al. there still is no gold standard in the treatment of acute AC joint injuries (9). Nowadays, the hook plate as well as arthroscopic or minimally invasive button techniques however seem to be the preferred techniques $(1,16)$ leading to good and reproducible clinical results.

\subsubsection{Postoperative Treatment}

There is no standardized concept for postoperative treatment. After hook plate implantation range of motion is usually restricted to $90^{\circ}$ of anteversion and abduction for the first 6 weeks. Contact sports and return to full activity is commonly allowed after plate removal 10 to 12 weeks postoperatively. Using a button technique the author recommends wearing a sling for 3 weeks and restricts range of motion to $90^{\circ}$ of abduction and anteversion for the first 6 weeks. From the 7th week on full range of motion is allowed and should be trained under guidance of a physiotherapist with emphasis on the scapulothoracic motion. Contact sports and full return to activities are allowed 4 months after surgery.

\subsection{Summary}

Based on the current literature there still is no gold standard for the diagnosis of acute AC joint injuries. Most authors recommend panorama-(stress-) view radiographs and additional radiographs for the horizontal instability. Low-grade injuries (Rockwood I-II) should be treated conservatively whereas high-grade injuries (Rockwood IV-VI) are best treated surgically. The most appropriate treatment for Rockwood III injuries is still a matter of debate and should be recommended based on the individual needs of the patient. There are numerous surgical techniques for treatment of acute injuries. Stabilization using the hook plate as well as arthroscopic button techniques are currently preferred leading to good and reproducible results.

\section{Conclusions}

Acute injuries of the AC joint are very common among active individuals. Low-grade injuries should be treated conservatively and high-grade injuries operatively. The treatment of Rockwood III injuries should be decided individually. The preferred diagnostics are panorama- (stress-) view radiographs combined by radiographs to detect potential horizontal instability. As surgical techniques, the hook plate as well as the arthroscopic button techniques are commonly used leading to good and reproducible results. However, evidence of the superiority of these techniques over alternative methods is lacking.

\section{Footnotes}

Authors' Contribution: None Declared.

Financial Disclosure: The authors certify that they have no financial disclosures.

\section{References}

1. Balke M, Schneider MM, Akoto R, Bathis H, Bouillon B, Banerjee M. Acute acromioclavicular joint injuries. Changes in diagnosis and therapy over the last 10 years [in German]. Unfallchirurg. 2015;118(10):851-7. doi:10.1007/s00113-013-2547-2. [PubMed: 24408200].

2. Bannister GC, Wallace WA, Stableforth PG, Hutson MA. The management of acute acromioclavicular dislocation. A randomised prospective controlled trial. J Bone Joint Surg Br. 1989;71(5):848-50. [PubMed: 2684990].

3. Imatani RJ, Hanlon JJ, Cady GW. Acute, complete acromioclavicular separation. J Bone Joint Surg Am. 1975;57(3):328-32. [PubMed: 1123385].

4. Larsen E, Bjerg-Nielsen A, Christensen P. Conservative or surgical treatment of acromioclavicular dislocation: A prospective, controlled, randomized study. J Bone Joint Surg Am. 1986;68(4):552-5. [PubMed: 3514625].

5. Bathis H, Tingart M, Bouillon B, Tiling T. Conservative or surgical therapy of acromioclavicular joint injury-what is reliable? A systematic analysis of the literature using "evidence-based medicine" criteria [in German]. Chirurg. 2000;71(9):1082-9. [PubMed: 11043125].

6. Phillips AM, Smart C, Groom AF. Acromioclavicular dislocation. Conservative or surgical therapy. Clin Orthop Relat Res. 1998(353):10-7. [PubMed: 9728155]. 
7. Taft TN, Wilson FC, Oglesby JW. Dislocation of the acromioclavicular joint. An end-result study. J Bone Joint Surg Am. 1987;69(7):1045-51. [PubMed: 3654696].

8. Gstettner C, Tauber M, Hitzl W, Resch H. Rockwood type III acromioclavicular dislocation: surgical versus conservative treatment. Shoulder Elbow Surg. 2008;17(2):220-5. doi: 10.1016/j.jse.2007.07.017. [PubMed: 18249565].

9. Beitzel K, Cote MP, Apostolakos J, Solovyova O, Judson $\mathrm{CH}$, Ziegler $\mathrm{CG}$, et al. Current concepts in the treatment of acromioclavicular joint dislocations. Arthroscopy. 2013;29(2):387-97. doi: 10.1016/j.arthro.2012.11.023. [PubMed: 23369483].

10. Cox JS. Current method of treatment of acromioclavicular joint dislocations. Orthopedics. 1992;15(9):1041-4. [PubMed: 1437863].

11. Powers JA, Bach PJ. Acromioclavicular separations. Closed or open treatment? Clin Orthop Relat Res. 1974(104):213-23. [PubMed: 4411824].

12. Bathis H, Tingart M, Bouillon B, Tiling T. The status of therapy of acromioclavicular joint injury. Results of a survey of trauma surgery clinics in Germany[in German]. Unfallchirurg. 2001;104(10):955-60. [PubMed: 11699305].

13. Rosslenbroich S, Wellmann M, Raschke MJ, Zantop T, Petersen W. Minimalinvasive Akromioklavikulargelenk-Rekonstruktion (MINAR). Obere Extremitat. 2009;4(3):154-9. doi: 10.1007/s11678-009-00366.

14. Elser F, Chernchujit B, Ansah P, Imhoff AB. [A new minimally invasive arthroscopic technique for reconstruction of the acromioclavicular joint]. Unfallchirurg. 2005;108(8):645-9. doi:10.1007/s00113-005-09330. [PubMed: 15915362].

15. Kraus N, Scheibel M. Treatment of acute acromioclavicular joint instability with modern reconstruction procedures [in German]. Unfallchirurg. 2012;115(10):872-8. doi: 10.1007/s00113-012-2248-2. [PubMed: 23007123].

16. Balke M, Schneider MM, Shafizadeh S, Bathis H, Bouillon B, Banerjee M. Current state of treatment of acute acromioclavicular joint injuries in Germany: is there a difference between specialists and non-specialists? A survey of German trauma and orthopaedic departments. Knee Surg Sports Traumatol Arthrosc. 2015;23(5):1447-52. doi: 10.1007/s00167-013-2795-2. [PubMed: 24306123].

17. Riand N, Sadowski C, Hoffmeyer P. [Acute acromioclavicular dislocations]. Acta Orthop Belg. 1999;65(4):393-403. [PubMed: 10675933].

18. Daly PJ, Sim FH, Simonet WT. Ice hockey injuries. A review. Sports Med. 1990;10(2):122-31. [PubMed: 2204098].

19. Sage FP, Salvatore JE. Injuries of the acromioclavicular joint: a study of results in 96 patients. South Med J. 1963;56:486-95. [PubMed: 13976050].

20. Webb J, Bannister G. Acromioclavicular disruption in first class rugby players. Br J Sports Med. 1992;26(4):247-8. [PubMed: 1490217].

21. Dias JJ, Gregg PJ. Acromioclavicular joint injuries in sport. Recommendations for treatment. Sports Med. 1991;11(2):125-32. [PubMed: 2017605].

22. Rowe CR. Acute and recurrent dislocations of the shoulder.J Bone Joint Surg Am. 1962;44-A:998-1008. [PubMed: 14038813].

23. Weaver JK. Skiing-related injuries to the shoulder. Clin Orthop RelatRes. 1987(216):24-8. [PubMed: 3815953].

24. Kocher MS, Dupre MM, Feagin JAJ. Shoulder injuries from alpine skiing and snowboarding. Aetiology, treatment and prevention. Sports Med. 1998;25(3):201-11. [PubMed: 9554030].

25. Kocher MS, Feagin JAJ. Shoulder injuries during alpine skiing. Am J Sports Med. 1996;24(5):665-9. [PubMed: 8883689].

26. Headey J, Brooks JH, Kemp SP. The epidemiology of shoulder injuries in English professional rugby union. Am J Sports Med. 2007;35(9):153743. doi: 10.1177/0363546507300691. [PubMed: 17452514].

27. Stuart MJ, Smith A. Injuries in Junior A ice hockey. A three-year prospective study. Am J Sports Med. 1995;23(4):458-61. [PubMed: 7573657].

28. Cadenat FM. The treatment of dislocations and fractures of the outer end of the clavicle. Int Clin. 1917;1:145-69.
29. Tossy JD, Mead NC, Sigmond HM. Acromioclavicular separations: useful and practical classification for treatment. Clin Orthop Relat Res. 1963;28:111-9. [PubMed: 5889033].

30. Rockwood CA. Injuries to the acromioclavicular joint. In: Rockwood CA, Green DP, editors. Fractures in adults. 2 ed. Philadelphia: JB Lip pincott; 1984. pp. 860-910.

31. Schneider MM, Balke M, Koenen P, Frohlich M, Wafaisade A, Bouillon $\mathrm{B}$, et al. Inter- and intraobserver reliability of the Rockwood classification in acute acromioclavicular joint dislocations. Knee Surg Sports Traumatol Arthrosc. 2016;24(7):2192-6. doi: 10.1007/s00167-014-3436-0. [PubMed: 25399347].

32. Scheibel M, Droschel S, Gerhardt C, Kraus N. Arthroscopically assisted stabilization of acute high-grade acromioclavicular joint separations. Am J Sports Med. 2011;39(7):1507-16. doi 10.1177/0363546511399379. [PubMed: 21436458].

33. Alexander OM. Radiography of the acromioclavicular articulation Med Radiogr Photogr. 1954;30(2):34-9. [PubMed: 13202745].

34. Zanca P. Shoulder pain: involvement of the acromioclavicular joint. (Analysis of 1,000 cases). Am J Roentgenol Radium Ther Nucl Med. 1971;112(3):493-506. [PubMed: 5570359].

35. Bucholz RW, Heckmann JD. Acromioclavicular joint injuries. In: Bucholz RW, Heckmann JD, Rockwood CA, Green DP, editors. Rockwood and Green's fractures in adults. Philadelphia: Lippincott Williams and Wilkins; 2001. p.1210-44.

36. Tauber M. Management of acute acromioclavicular joint dislocations: current concepts. Arch Orthop Trauma Surg. 2013;133(7):985-95. doi: 10.1007/s00402-013-1748-z. [PubMed: 23632779].

37. Barnes CJ, Higgins LD, Major NM, Basamania CJ. Magnetic resonance imaging of the coracoclavicular ligaments: its role in defining pathoanatomy at the acromioclavicular joint. J Surg Orthop Adv. 2004;13(2):69-75. [PubMed: 15281402].

38. Antonio GE, Cho JH, Chung CB, Trudell DJ, Resnick D. Pictorial essay. MR imaging appearance and classification of acromioclavicular joint injury. AJR Am J Roentgenol. 2003;180(4):1103-10. doi 10.2214/ajr.180.4.1801103. [PubMed: 12646463].

39. Schaefer FK, Schaefer PJ, Brossmann J, Hilgert RE, Heller M, Jahnke T. Experimental and clinical evaluation of acromioclavicular joint structures with new scan orientations in MRI. Eur Radiol 2006;16(7):1488-93. doi: 10.1007/s00330-005-0093-1. [PubMed: 16435136].

40. Alyas F, Curtis M, Speed C, Saifuddin A, Connell D. MR imaging appearances of acromioclavicular joint dislocation. Radiographics. 2008;28(2):463-79. doi: 10.1148/rg.282075714. [PubMed: 18349451] quiz 619.

41. Varney JH, Coker JK, Cawley JJ. Treatment of acromioclavicular dislocation by means of a harness. J Bone Joint Surg Am. 1952;34-A(1):232-3. [PubMed: 14907812].

42. Spigelman L. A harness for acromioclavicular separation. J Bone Joint Surg Am. 1969;51(3):585-6. [PubMed: 5781592].

43. Darrow JCJ, Smith JA, Lockwood RC. A new conservative method for treatment of Type III acromioclavicular separations. Orthop Clin North Am. 1980;11(4):727-33. [PubMed: 7454243].

44. Urist MR. Complete dislocations of the acromiclavicular joint; the nature of the traumatic lesion and effective methods of treatment with an analysis of forty-one cases. J Bone Joint Surg Am. 1946;28(4):813-37. [PubMed: 21003194].

45. Mouhsine E, Garofalo R, Crevoisier X, Farron A. Grade I and II acromioclavicular dislocations: results of conservative treatment. J Shoulder Elbow Surg. 2003;12(6):599-602. doi: 10.1016/S1058274603002155. [PubMed: 14671526].

46. Mikek M. Long-term shoulder function after type I and II acromioclavicular joint disruption. Am J Sports Med. 2008;36(11):2147-50. doi: 10.1177/0363546508319047. [PubMed: 18583520].

47. Balser D. Eine neue Methode zur operativen Behandlung der akromioklavikularen Luxation. Chir Prax. 1976;24:275-81. 
48. Kienast B, Thietje R, Queitsch C, Gille J, Schulz AP, Meiners J. Mid-term results after operative treatment of rockwood grade III-V acromioclavicular joint dislocations with an AC-hook-plate. Eur J Med Res. 2011;16(2):52-6. [PubMed: 21463981].

49. Salem KH, Schmelz A. Treatment of Tossy III acromioclavicular joint injuries using hook plates and ligament suture. J Orthop Trauma. 2009;23(8):565-9. doi: 10.1097/BOT.0b013e3181971b38. [PubMed: 19704271].

50. Di Francesco A, Zoccali C, Colafarina O, Pizzoferrato R, Flamin S. The use of hook plate in type III and V acromio-clavicular Rockwood dislocations: clinical and radiological midterm results and MRI evaluation in 42 patients. Injury. 2012;43(2):147-52. doi: 10.1016/j.injury.2011.04.002. [PubMed: 21592473].

51. Chiang CL, Yang SW, Tsai MY, Kuen-Huang Chen C. Acromion osteolysis and fracture after hook plate fixation for acromioclavicular joint dislocation: a case report. J Shoulder Elbow Surg. 2010;19(4):13-5. doi: 10.1016/j.jse.2009.12.005. [PubMed: 20303294].

52. Wolf EM, Pennington WT. Arthroscopic reconstruction for acromio clavicular joint dislocation. Arthroscopy. 2001;17(5):558-63. doi 10.1053/jars.2001.23578. [PubMed: 11337730].

53. Zooker CC, Parks BG, White KL, Hinton RY. TightRope versus fiber mesh tape augmentation of acromioclavicular joint reconstruction a biomechanical study. Am J Sports Med. 2010;38(6):1204-8. doi:
10.1177/0363546509359064. [PubMed: 20392969].

54. Klimkiewicz JJ, Williams GR, Sher JS, Karduna A, Des Jardins J, Iannotti JP. The acromioclavicular capsule as a restraint to posterior translation of the clavicle: a biomechanical analysis. J Shoulder Elbow Surg. 1999;8(2):119-24. [PubMed: 10226962].

55. Petersen W, Wellmann M, Rosslenbroich S, Zantop T. Minimally Invasive Acromioclavicular Joint Reconstruction (MINAR) [in German]. Oper Orthop Traumatol. 2010;22(1):52-61. doi: 10.1007/s00064-0103004-4. [PubMed: 20349170].

56. Tischer T, Salzmann GM, El-Azab H, Vogt S, Imhoff AB. Incidence of associated injuries with acute acromioclavicular joint dislocations types III through V. Am J Sports Med. 2009;37(1):136-9. doi: 10.1177/0363546508322891. [PubMed: 18725652].

57. Pauly S, Kraus N, Greiner S, Scheibel M. Prevalence and pattern of glenohumeral injuries among acute high-grade acromioclavicular joint instabilities. J Shoulder Elbow Surg. 2013;22(6):760-6. doi: 10.1016/j.jse.2012.08.016. [PubMed: 23021905].

58. Jensen G, Katthagen JC, Alvarado LE, Lill H, Voigt C. Has the arthroscopically assisted reduction of acute AC joint separations with the double tight-rope technique advantages over the clavicular hook plate fixation? Knee Surg Sports Traumatol Arthrosc. 2014;22(2):422-30. doi: 10.1007/s00167-012-2270-5. [PubMed: 23124627]. 